\title{
Review
}

\section{Excessive subjectivity: Kant, Hegel, Lacan, and the foundations of ethics}

\author{
Dominik Finkelde \\ New York, Columbia University Press, 2017, xiii+340 pp., \\ ISBN: 978-0-231-17318-6
}

Contemporary Political Theory (2019) 18, S290-S293. https://doi.org/10.1057/s41296018-0227-2; published online 18 May 2018

Over the past two decades, an innovative reading of German idealist philosophers through the lens of French psychoanalyst Jacques Lacan's work has achieved some prominence in discussions of political theory. This has been primarily credited to Slavoj Žižek's charisma, and his penchant for illustrating his ideas with examples from popular culture. To some extent this prominence in the media may detract from reflection on the merit of the ideas, which have considerable effect on the understanding of the transcendental idealism of Immanuel Kant, the dialectics of G.W.F. Hegel, and the political ramifications of an adherence to these authors' frameworks. Dominik Finkelde has done a great service by elucidating the stakes of the encounter between German idealism and French psychoanalysis, as well as its implications. Rather than popularizing the claims by reference to pop culture, he makes considerable effort to engage with mainstream German and U.S. scholarship on these authors. His contribution here gives us a compelling and serious account of how Kant, Hegel, and Lacan might be brought together, despite the apparent dissimilarities among their approaches. However, Finkelde's political examples most frequently, his reference to the figure of Rosa Parks - remain abstract, and lack thorough engagement with particular strategies and purposes. I suggest that his approach ought to be supplemented by further guiding principles that elucidate the political procedures most likely to produce just outcomes.

Finkelde intervenes in the standard understanding of Kant's ethics as formal, contrasting with Hegel's pragmatic approach (pp. 2-3). He identifies between the two of them, in contrast, a shared recognition of 'excessive subjectivity,' in which indeterminacy of the law gives way to an ethical act. Finkelde draws on the early critical Kant to uncover an 'aporectic split' in moral action (p. 5). Hegel relies on this insight in order to describe a potential 'situation of unlegalizable indeterminacy', in which a political actor is 'capable of overextending the established episteme toward a new horizon of meaning' (p. 4). Contrary to a more standard understanding of Kant's ethics as conformist, Finkelde draws out implications in

(C) 2018 Macmillan Publishers Ltd., part of Springer Nature. 1470-8914 Contemporary Political Theory Vol. 18, S4, S290-S293 www.palgrave.com/journals 
his work that suggest that in some instances an ethical act can appear irrational or extreme (p. 39).

Finkelde argues that this excess is then registered in Lacan's psychoanalytic investigations. He suggests a view of the subject that appears at first glance very different from Kant's and Hegel's usual emphasis on obedience to norms; Lacan's subject is a paradoxical effect of an inexorable conflict between norm and transgression (p. 152). He brings the alternative ethical frameworks together by suggesting that a subject's potential for transgression of the law is necessary to inaugurate a new social order; it is the only way to correct a legal system that might be later recognized as unjust (pp. 70-71).

This is the strongest case in the book. Finkelde counters traditional and contemporary accounts of Kant and Hegel that make their ethico-political thought into a matter of following pre-given social norms. He reads their work carefully, and engages with the history of interpretation so as to argue the necessity of moments in which social norms must be questioned and replaced. In these moments, he identifies a dimension of excess that cannot be pre-judged by convention. Finkelde presents a critical rejoinder to Robert Brandom's analytic pragmatism, which attempts to reveal the rational norms of practices (p. 68). In contrast to Brandom's appeal to Kant and Hegel, Finkelde's reading demonstrates the limits of such an approach, and points to a continual potential for disruption. This is an important challenge to deterministic readings of the German idealist tradition, and one that has considerable practical consequences.

In order to illustrate this possibility in practical history, Finkelde often refers to the case of Rosa Parks' exemplary act during the civil-rights movement: her refusing to give up her seat for a white passenger (pp. 9, 72-73). Finkelde's invocation of this moment has considerable stakes, in framing his political philosophy as a theory of civil disobedience. Finkelde emphasizes a profound ethical indeterminacy in Parks' refusal; he says that, at the moment of her action in 1955, it was not clear 'whether her deed was a fundamentally erroneous interpretation of the local public transportation rules of the state of Alabama or whether it was an expression of moral courage against segregation' (p. 72). While he realizes that many other civil-rights activists agreed with the rightness of her obstinacy, the practical enactment of this conviction, for him, must be seen as initially illegal and uncertain in its morality (p. 73). However, the passage of time and history retroactively changes this act into an instantiation of a new social order of norms, one in which Black people cannot be arbitrarily ordered to give up their seating (p. 81). Finkelde makes this the paradigm for successful civil disobedience, for which he finds grounding in the political philosophy of Kant and Hegel and the psychoanalytic ethics of Lacan.

I have a few difficulties with this framing that I will enumerate here. First, Finkelde seems to conflate Lacan's concerns, primarily with an individual's psychic constitution and the harnessing of libidinal energies, with the somewhat

(C) 2018 Macmillan Publishers Ltd., part of Springer Nature. 1470-8914 Contemporary Political Theory Vol. 18, S4, S290-S293 S291 
different problem of a citizen's relation to a state's legal order. Finkelde recognizes that Lacan's concept of Law refers to an 'original psychic mechanism that first makes subjectivity possible through the enigmatic emergence of norm recognition,' not the particular legislation of any given jurisdiction (p. 14). However, his example seems to elide this distinction. The question of Rosa Parks' psychic economy of desire might be quite different from her choice of political action.

Second, I think Finkelde's framework seems to place too much importance on the concrete success of the ethico-political act in reforming the legal code. For example, he writes, 'Rosa Parks brought the culture of the Southern states over to her side' (p. 81). It is true that Parks successfully challenged the rule according to which Black people could be moved to the back of the bus, but the goal of her action went much further than that. I am not convinced that Southern (or U.S. American) culture has, in fact, recognized the human rights of Black people. If Parks' action is read as limited to this particular rule, this limits the excessive dimension of her conduct. As a more general principle, I think that a political act may be formally correct, even if it is not practically successful in modifying civil law. For example, the failure to accomplish a socialist society does not in itself render socialist ideas incorrect.

Finkelde also makes a comparison that seems a bit extravagant, indicating that much more drastic acts of insurrection are formally indistinguishable from Parks' tactics. He suggests that the activities of the Red Army Faction, the German militant organization of the 1970s, were philosophically congruent with Parks' example, in many respects. The difference between them, he argues, is in the outcome: Parks succeeded in social recognition of the justice of her claim while the RAF did not (p. 228). The moderate and non-violent nature of Parks' resistance is clearly very different from the bombings and robberies practiced by the RAF. While we might recognize a formal 'terrorism' of the two procedures in that both interrupt normal civil functioning, the differences in practical strategy are so great that the comparison risks exaggerated abstraction. In general, I think more attention to Parks' political development and self-reflection might further delineate the stakes of her activity and the long-term political effects it was meant to have.

In general, Finkelde's appreciation of civil disobedience seems to gesture toward left-wing application; he also dedicates the book to Rachel Corrie, who died defending Palestinian households, and makes reference to the recent information leaks disseminated by Chelsea Manning and Edward Snowden (p. 241). Nonetheless, the theory does not give any register for determining outcomes or methods that could be anticipated as just. For this reason, it seems that it could be extended to include reactionary political purposes. Finkelde makes a strong case for the occasional necessity to exceed previous norms given by law in order to achieve a new form of justice that avoids conventional exclusions. However, I think that more philosophical work should be done to delimit the instances of law-breaking

S292 (c) 2018 Macmillan Publishers Ltd., part of Springer Nature. 1470-8914 Contemporary Political Theory Vol. 18, S4, S290-S293 
that are most likely to achieve a just outcome, even if we can never entirely guarantee their successful recognition by the social order.

Andrew Ryder

Texas Christian University, Fort Worth, TX 76129, USA

a.h.ryder@tcu.edu 